\title{
HERMETIC STORAGE: A NOVEL APPROACHTO THE PROTECTION OF COCOA BEANS
}

\author{
W. JONFIA-ESSIEN, SHLOMO NAVARRO ${ }^{1}$ and P. VILLERS ${ }^{2}$ \\ Research Department, Quality Control Company Ltd. (COCOBOD), P. O. Box CO 247, Tema, Ghana \\ ${ }^{1}$ Food Technology International Consultancy Ltd., Israel \\ ${ }^{2}$ GrainPro, Inc., 200 Baker Avenue, Concord, MA 01742 \\ Corresponding author: wajonfiaessien@gmail.com
}

(Received14 January, 2010; accepted 26 May, 2010)

\begin{abstract}
Hermetic storage has provided a successful storage method for protection of commodities without fumigants or need for refrigeration for insect control and quality preservation of stored products. Hermetic storage is achieved in specially constructed plastic structures for the preservation of cereal grains and other commodities. Plastic structures suitable for long-term storage systems, as well as intermediate storage of grain have been developed and applied. These storage systems based on the hermetic principle were designed for (1) storage at the farmercooperative and small trader level with 10 - 1000 tonnes capacity for enclosing stacks termed Cocoons ${ }^{\mathrm{TM}}$, (2) small scale storage suitable for small portable containers of $60 \mathrm{~kg}$ to 2 tonnes called SuperGrainbags ${ }^{\mathrm{TM}}$ and (3) quality preservation, insect control and prevention of condensation during shipment of commodities in shipping containers known as TranSafeliners ${ }^{\mathrm{TM}}$. Hermetic storage is based on the principle of generation of an oxygendepleted, carbon dioxide-enriched interstitial atmosphere caused by the respiration of the living organisms in the ecological system of a sealed storage. A sufficiently low oxygen and elevated CO2, atmosphere is created through a natural metabolic process based on insect respiration and, in cases where the commodity has sufficiently high moisture, the respiration of the microorganisms within a sealed storage system. Applications for which hermetic technology has been most widely accepted are long-term storage of cereal grains, primarily rice, corn, barley, wheat and a variety of seeds to preserve germination potential and vigor and quality preservation of high-value commodities such as cocoa and coffee. Under field conditions in a cocoa bean storage facility in Makassar, Indonesia, a hermetically sealed flexible structure containing 6.7 tonnes of cocoa beans at an initial moisture content of $7.3 \%$ and relative humidity of $70 \%$ was monitored for oxygen concentration and quality parameters of the beans. The measurements showed a decrease in oxygen concentration to $0.3 \%$ after 5.5 days. No insects survived the oxygen depleted biogenerated atmosphere. Similar trials were carried out in Ghana by COCOBOD in which three stacks for hermetic storage and one stack each for conventional storage (without fumigation) and standard storage (with fumigation) were built for sampling and observation. At the sixth week of storage $100 \%$ mortality of insects was recorded in the Cocoon ${ }^{\mathrm{TM}}$. All the cocoa beans inside the Cocoon ${ }^{\mathrm{TM}}$ maintained their quality category throughout the storage period and the grade remained the same after nine weeks of storage as it was at the beginning of the experiment.
\end{abstract}

Key Words: Coffee, cocoa beans, hermetic storage, insects, modified atmospheres, quality preservation, seeds, storage

\section{RÉSUMÉ}

Le stockage hermétique constitue une méthode satisfaisante de stockage pour la protection des produits sans recours aux fumigènes et à la refrigeration, pour le contrôle des insectes et la preservation de la qualité des produits stockés. Le stockage hermétique est réalisé par la construction des structures en plastique, spécialement pour la conservation des grains de céréales et autres denrées. Des structures en plastique appropriées aux systèmes de 
stockage de grains à long aussi bien qu’à moyen terme ont été développées et appliquées. Basés sur le principe hermétique, ces systèmes de stockage étaient conçus pour (1) le stockage au niveau de coopératives de fermiers et de petits commerçants avec une capacité de 10 - 1000 tonnes pour enfermer des piles ont nommé Cocoons ${ }^{\mathrm{TM}}$, (2) stockage à petite échelle appropriée aux petits conteneurs portables de $60 \mathrm{~kg}$ à 2 tonnes appelés SuperGrainbags ${ }^{\mathrm{TM}}$ et (3) la preservation de la qualité, lutte contre les insectes et la prévention de la condensation lors du transport des produits dans des conteneurs connus sous le nom de TranSafeliners ${ }^{\mathrm{TM}}$. Le stockage hermétique est basé sur le principe de génération d'oxygène appauvri, un atmosphere intersticiel enrichi en dioxyde de carbone par la respiration des organismes vivant dans le système écologique du stockage scellé. Il en résulte un atmosphere suffisamment deficient en oxygène, avec un taux élevé de CO2 par suite du processus naturel de métabolisme basé sur la respiration des insectes et, dans les cas où les produits ont une humidité suffisamment élevée, la respiration des microorganismes dans le système de stockage hermétique. Les applications de la technologie hermétique les plus largement acceptées sont le stockage à long terme des grains de céréales principalement le riz, le maïs, l'orge, le blé et la preservation de la viguer et du potential de germination de semences variées, ainsi que la preservation de la qualité des produits de grande valeur tels que le cacao et le café. En conditions de terrain dans une installation de stockage de fèves de cacao à Makassar en Indonésie, une étude a été faite sur la concentration de l'oxygène et les paramètres de qualité des grains dans structure flexible hermétiquement fermée contenant 6,7 tonnes de fèves de cacao ayant une teneur initiale en eau de 7,3\% et une humidité relative de $70 \%$. Des mesures effectuées ont montré une diminution de $0,3 \%$ de la concentration en oxygène après 5,5 jours. Aucun insecte n'a pu survivre à la biogénération de l'atmosphère appauvri en oxygène. Des essais similaires ont été menés au Ghana par COCOBOD, par lesquels trois piles pour le stockage hermétique et une pile de stockage conventionnel pour chacun (sans fumigation) et le stockage standard (avec la fumigation) étaient construits pour l'échantillonnage et l'observation. À la sixième semaine de stockage, $100 \%$ de cas de mortalité des insectes était enregistré dans le CocoonTM. Toutes les fèves de cocoa à l'intérieur du CocoonTM maintainaient leur catégorie de qualité tout au long de la période de stockage et la qualité est restée la même après neuf semaines de stockage tel qu'il était au début de l'expérience.

Mots Clés: Atmosphères modifiées, café, preservation de qualité, insecte de stockage, semence

\section{INTRODUCTION}

A new approach to cocoa bean storage, "hermetic storage" (HS), has been investigated in both laboratory and field studies to protect them both in storage and in transit, and is now in commercial use in Africa, Asia and Latin America. Hermetic storage is a type of modified atmosphere (MA) that has now been applied for the protection of stored agricultural commodities including cocoa beans, coffee, rice, corn, pulses and seeds (Navarro et al., 1984; 1993; 1995; Varnava and Mouskos, 1997; Navarro, 2006; Sabio et al., 2006). It is also called "sealed storage" or "air-tight storage" or "sacrificial sealed storage" or "hermetic silo storage". This method takes advantage of sufficiently sealed structures that enable insects and other aerobic organisms in the commodity or the commodity itself to generate the MA by reducing the $\mathrm{O}_{2}$ and increasing the $\mathrm{CO}_{2}$ concentrations through respiratory metabolism. It has been shown that hermetic storage allows safe storage for periods ranging from weeks to many months, as well as during shipment across intercontinental distances. Hermetic storage provides protection of cocoa beans without the need for chemicals, cold storage chambers or refrigeration, and maintains a constant moisture level in the cocoa beans regardless of the exterior air composition.

Infestation is a major problem and therefore the beans are frequently fumigated using phosphine or methyl bromide (MB). Fumigants are widely used for pest control both in cocoa beans and also in other stored products to prevent quantitative and quality losses caused by insect pests. However, increased public concern over the adverse effects of pesticide residues in food and the environment has led to their partial substitution with alternative control methods. Consequently, non-chemical and environmentally user-friendly methods of pest control in the post harvest sector are becoming increasingly important. MB should have been phased out in developed countries by 2005 and will be phased out in developing countries by 
2015, because of its contribution to stratospheric ozone depletion (UNEP, 2002). In contrast, phosphine remains popular, particularly in developing countries, because it is easier to apply than MB. However, some insects have developed resistance to phosphine in some countries over the last decade (Cao et al., 2003; Savvidou et al., 2003).

Storage problems prevail in the presence of adequate oxygen and temperature. This presents and promotes the growth of insect population and in the presence of high relative humidity molds develop to cause quality deterioration resulting in an increase in free fatty acids (FFAs), rancidification of flavour and mycotoxins. These postharvest problems are eliminated through the lethal effect of a low $\mathrm{O}_{2}$ /high $\mathrm{CO}_{2}$ atmosphere produced through respiration processes. Under hermetic conditions, stored commodities with intermediate moisture contents generate modified atmospheres due to the respiration of the microflora and the commodity itself. The objective of this study was to provide data on the novel approach of using hermetic storage based solely on biogenerated modified atmospheres as an insect control, and quality preservation method for stored cocoa beans and other stored agricultural products.

\section{Storage structures and enclosures developed for} hermetic storage. Modern hermetic storage systems (HS) for cocoa and other commodities use special low permeability flexible plastic enclosures. These hermetic storage containers have evolved to store a variety of dry commodities in the range of $60 \mathrm{~kg}$ to 10,000 tonnes. They became commercially available starting in the early 1990's, and today are in use in more than 38 countries in a variety of configurations.

In order to fill the growing range of requirements, hermetic storage is used in a number of different forms. Most often, these systems rely purely on biological effect of respiration of the commodity and of infesting insects to create the desired low oxygen modified atmosphere. However, a few specialised applications require more rapid disinfestation, such as in 3 days for dried figs (Ferizli and Emekci, 2000). In these, oxygen levels are reduced more rapidly, either by purging with $\mathrm{CO}_{2}$ (Gas - Hermetic Fumigation “G-HF”), or by applying a significantly high vacuum (Vacuum - Hermetic Fumigation "V-HF”). In either case, the process can quickly reduce oxygen content to below 1\% to 2\% (Navarro et al., 2002; Villers et al., 2006).

The most widely used form of HS is the Cocoon $^{\mathrm{TM}}$ (Fig. 1). It is manufactured in capacities ranging from 5 to 300 tonnes. Cocoons, used for storing cocoa and other commodities, are made from specially formulated flexible $0.83 \mathrm{~mm}$ thick PVC with permeability to oxygen of $400 \mathrm{cc} \mathrm{m}^{-2}$ day $^{-1}$ and to water vapour of $8 \mathrm{~g} \mathrm{~m}^{-2}$ day $^{-1}$. They are sealed with an airtight zipper originally developed for use by astronauts.

A newer type of Cocoon called the MegaCocoon ${ }^{\mathrm{TM}}$ has more recently been introduced for larger scale storage of up to 1050 tonnes, with initial installations in Sudan (Fig. 2). For smaller unit containers of $60 \mathrm{~kg}$ to $90 \mathrm{~kg}$ capacity, a 150 g weighing highly transportable SuperGrainbag ${ }^{\text {TM }}$ (SGB) is used (Fig. 3). The SGB

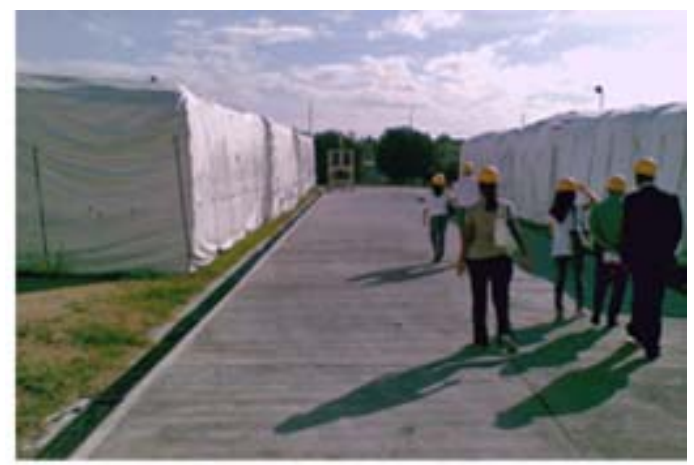

Figure 1. Outdoor storage in cocoons ${ }^{\mathrm{TM}}$, Philippines, 2008. 


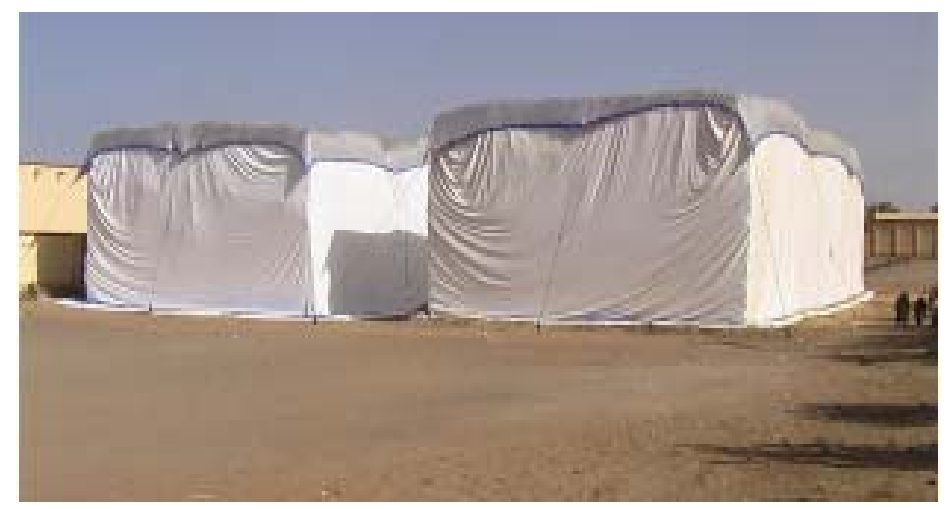

Figure 2. 1050 Tonne MegaCocoon ${ }^{\mathrm{TM}}$, Sudan, 2009.

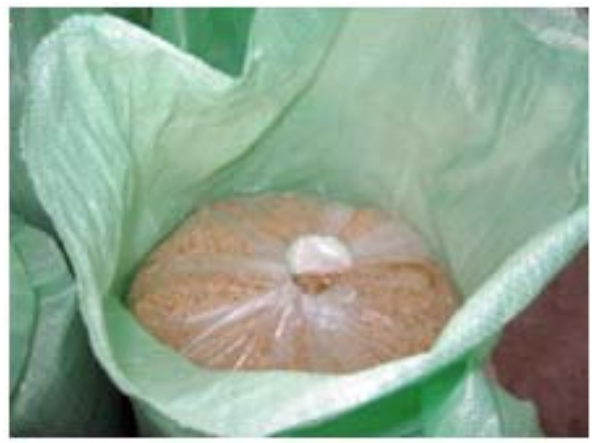

Figure 3. Hermetically sealed SuperGrainbag ${ }^{\mathrm{TM}}$ with corn seeds inside a woven polypropylene bag.

is a 3-layer coextruded plastic with thickness of $0.078 \mathrm{~mm}, 3 \mathrm{cc} \mathrm{m}^{-2}$ day $^{-1}$ permeability levels for oxygen and for water vapour of $8 \mathrm{~g} \mathrm{~m}^{-2}$ day $^{-1}$. These features of SGB maintain commodity quality, even with long transport times and in humid environments.

More recently using the same material, the SuperGrainbags-HC ${ }^{\text {TM }}$ has become available for use with mechanized loading, which handles up to a 2-tonne capacity for bags or bulk storage (Fig. 4). To protect bagged or bulk commodities against damage and deterioration when shipping across intercontinental distances in 20- and 40foot standard shipping containers, the TranSafeliner ${ }^{\mathrm{TM}}$ was introduced in 2008 (GrainPro, 2008) (Fig. 5). The TranSafeliner provides hermetic storage during transport in a standard shipping container using the same type of ultra low permeability co-extruded plastic used in the SuperGrainbag (Fig. 3) (Villers et al., 2008). These various forms of hermetic storage are now used for a number of different commodities. The most common current uses other than for cocoa are for the protection of paddy, milled rice, brown rice, corn, wheat, sorghum, pulses, seeds of many types, and coffee. The hermetic barrier materials used are most often either the $0.83 \mathrm{~mm}$ thick PVC Cocoon $^{\mathrm{TM}}$ shown in Figure 1 with a permeability to oxygen of $400 \mathrm{cc} \mathrm{m}^{-2}$ day $^{-1}$ and to water vapor of $8 \mathrm{~g} \mathrm{~m}^{-2}$ day $^{-1}$, or the $0.078 \mathrm{~mm}$ co-extruded polyethylene with a proprietary ultra low permeability barrier material as middle layer such as shown in SuperGrainbags ${ }^{\mathrm{TM}}$ (Fig. 3) with a permeability to oxygen ranging down to $3 \mathrm{cc} / \mathrm{m}^{2} /$ day, and to water vapor of $8 \mathrm{~g} \mathrm{~m}^{-2}$ day $^{-1}$.

Preservation of stored cocoa beans. The problem of moisture in non-hermetic storage is well understood. Intermediate moisture contents of stored commodities at equilibrium with relative humidity of 65 to $75 \%$ of stored commodities are inevitable in tropical climates (Transport Information Service, 2009). Under hermetic conditions, stored commodities with intermediate 


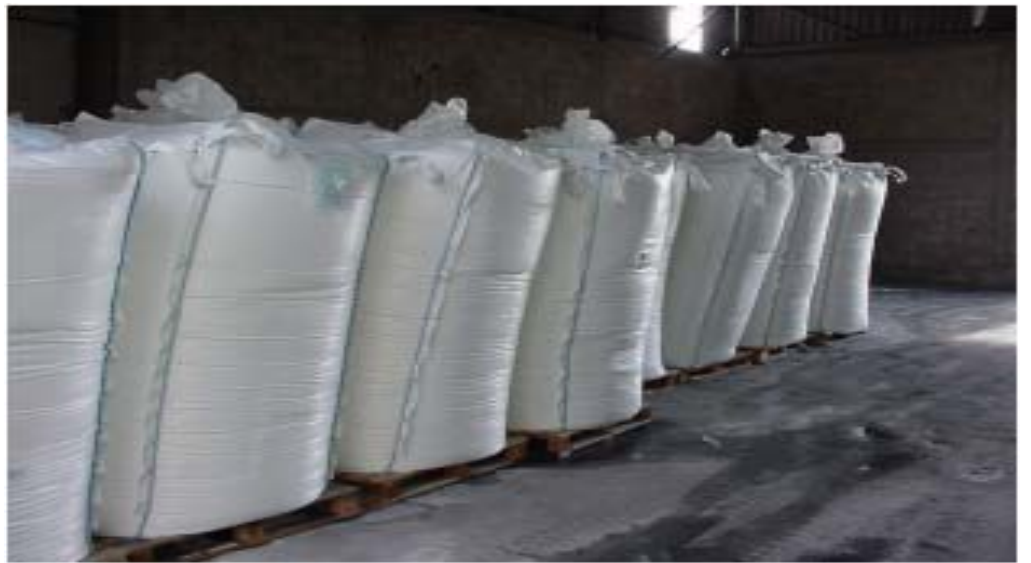

Figure 4. One tonne SuperGrainbags- $\mathrm{HC}^{\mathrm{TM}}$ storing paddy with woven inside protective polypropylene bag.

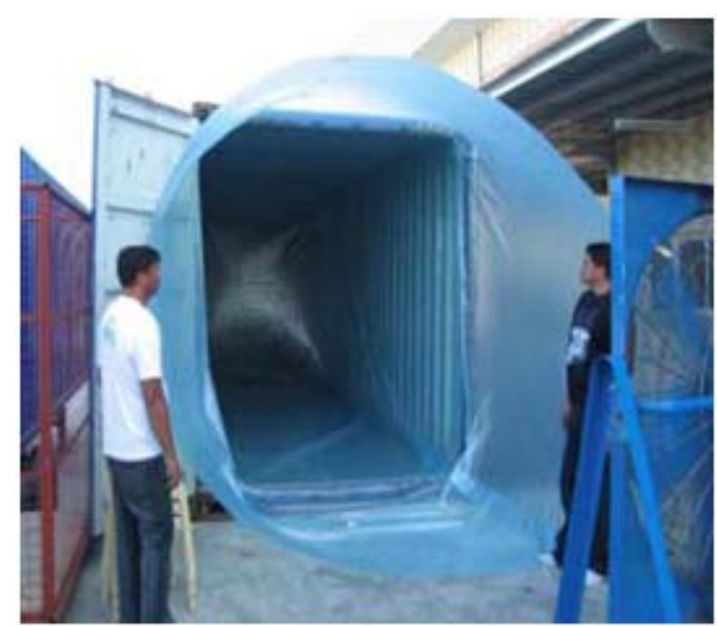

Figure 5. TranSafeliner ${ }^{\mathrm{TM}}$ being installed in a standard shipping container, 2008.

moisture contents generate modified atmospheres due to the respiration of the microflora and the commodity itself. Data were compiled for insect control and for quality preservation of stored cocoa beans by employing a novel approach through the use of bio-generated modified atmospheres as a methyl bromide alternative. The respiration rates of fermented cocoa beans at equilibrium relative humidities of $73 \%$ at $26^{\circ} \mathrm{C}$ in hermetically sealed containers depleted the oxygen concentration to $<0.3 \%$ and increased the carbon dioxide concentration to $23 \%$ within 5.5 days. This hermetically sealed flexible structure contained 6.7 tonnes of cocoa beans at moisture content of $7.3 \%$. It was monitored for oxygen concentration and quality parameters of the beans (Fig. 6). No insects survived the oxygen depleted bio-generated atmosphere. These encouraging results reveal the possibility of utilising bio-generated atmospheres in integrated pest management (IPM) for quality preservation by preventing the development of moulds, FFA and mycotoxins and insect control of cocoa pests. (Navarro et al., 2007). Hermetic liners for $20 \mathrm{ft}$. containers such as the TranSafeliner ${ }^{\mathrm{TM}}$ are now increasingly used for maintaining quality in international shipments of cocoa beans and coffee.

Laboratory data on hermetic storage of cocoa. Cocoons were first used for cocoa storage in Indonesia in 2005, and in the same year were the subject of a detailed laboratory study in Israel at its Agricultural Research Organization (ARO). 
The study's report describes hermetic storage as a method of quality preservation of stored cocoa beans methyl bromide a novel approach through the use of bio-generated modified atmospheres. The respiration effect of fermented cocoa beans from Makassar, Sulawesi, Indonesia, was determined under laboratory conditions. Initial insect populations found in these cocoa beans samples consisted of Carpophilus spp., Ahasverus advena, Cryptolestes spp. and Psocids. The effects of cocoa beans at equilibrium relative humidities (r.h.) of 59, 68, and $73 \%$ were determined at $26^{\circ} \mathrm{C}$ in hermetically sealed 1-liter capacity jars containing $500 \mathrm{~g}$ of the commodity. At the equilibrium r.h. of $73 \%$, the respiration of the cocoa beans depleted the oxygen concentration to $<1 \%$ and increased the carbon dioxide concentration to $23 \%$ within six days. However, to obtain similar oxygen depletion for drier cocoa beans at $68 \%$ equilibrium r.h., a duration of 23 days was required, while for the sealed cocoa beans in equilibrium with 59\% r.h. the oxygen concentration after 23 days had only decreased to $10.8 \%$ (Navarro et al., 2007).

Field experience from Indonesia. The field trial was carried out in a warehouses located in
Makassar (Ujung Pandang), Indonesia from June to November 2005. The trial consisted of storing locally available bagged cocoa beans in a gastight sealed flexible GrainPro Cocoon of $15 \mathrm{~m}^{3}$ capacity. The Cocoon accommodated 108 jute bags of cocoa beans each of $62.5 \mathrm{~kg}$ capacity. The initial moisture content (m.c.) of the Cocoon $^{\mathrm{TM}}$ was determined on ten samples taken from the bottom, middle and top layers of the stack. The average m.c. of each sample was taken at the start of the trial in June and at the end of the trial.

The initial moisture content of 7.3\% (70\% equilibrium r.h.) was monitored for oxygen concentration and quality parameters of the beans. The measurements showed a decrease in oxygen concentration to $0.3 \%$ after 5.5 days (Fig. $6)$. An ambient temperature of $30^{\circ} \mathrm{C}$ was maintained through out the six months period. The cocoa bean samples showed a slight increase in moisture content from 7.3 to $7.7 \%$, thus 70 to $73 \%$ equilibrium r.h. Such an oxygen depleted atmosphere was sufficient to control the existing insect population and no live insects were recorded in the ten cocoa bean samples at the opening of the Cocoon in November.

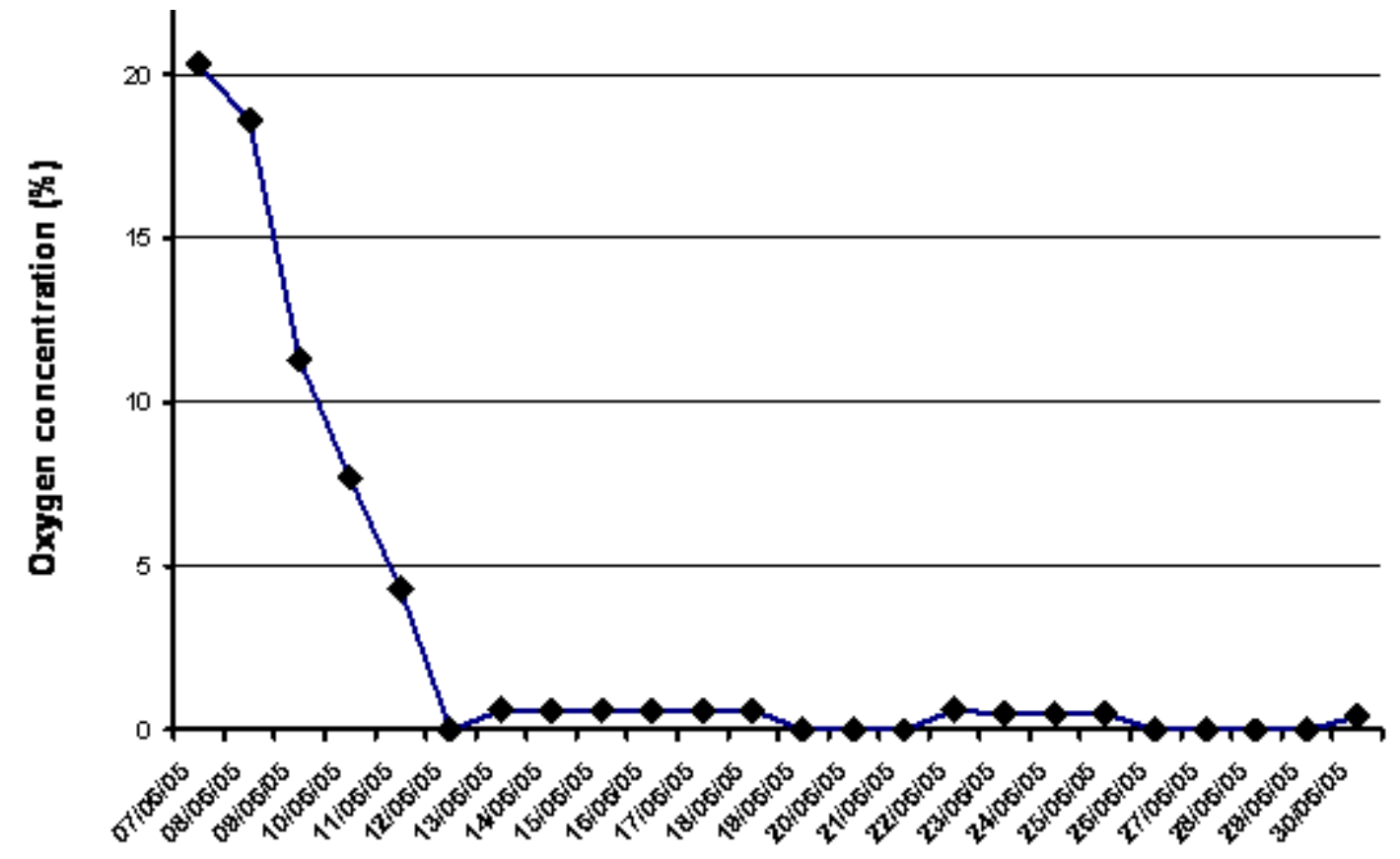

Figure 6. Changes in oxygen concentration in cocoa beans, Makassar, Indonesia, 2005 (Navarro et al., 2007). 
Field experience from Ghana. Three stacks for hermetic storage and one stack each for conventional storage (without fumigation) and standard storage (with fumigation) were built for the experiment. The Cocoon stacks were $3.40 \mathrm{~m}$ long x $2.95 \mathrm{~m}$ wide x $2.0 \mathrm{~m}$ high, and contained 220 bags (64 kg per bag) of sun-dried (average of $7.0 \%$ moisture content) cocoa beans. Oxygen concentration and temperature inside the stack of cocoa beans were monitored daily. Sampling was done at 0, 3, 6 and 9 weeks intervals for insect density and quality characterisation. A steep decline in oxygen concentration was observed in all Cocoons during the storage with a concentration of $0.0 \%$ being recorded in all the Cocoons from the fifteenth day of storage and this was maintained throughout the storage period (Fig. 7). The temperature was almost uniform inside the Cocoon throughout the storage period. After three weeks of storage, the first Cocoon was infested with live adults of Cryptolestes ferrugineus, Cryptolestes pusillus, Araecerus fasciculatus, Lasioderma serricorne, and Ephestia cautella larvae and some fruit flies. However, most of the insects died inside the Cocoons. Most of the Lasioderma serricorne and Tribolium castaneum introduced at the beginning of the experiment were dead at the third week and $100 \%$ of all the types of insects were dead by the sixth week of storage (Table 1). All the cocoa beans inside the Cocoon maintained their quality category throughout the storage period and the grade remained the same after nine weeks of storage as it was at the beginning of the trial. (Jonfia-Essien et al., 2008a).

This was not the case in both the control/ conventional and standard experiments in which the oxygen concentration remained virtually the same. The steep decline in oxygen concentration in all Cocoons during the storage is an indication that the organisms including insects present in the Cocoon exhibited significantly high rate of respiration, which is a major factor in the consumption of oxygen. The Cocoon prevented gas exchange between the plastic enclosure and the external environment and therefore a depleted oxygen atmosphere was created.

The Ghana Cocoa Board also evaluated the use of hermetic SuperGrainbag (SGB) liners inside conventional jute bags of $70 \mathrm{~kg}$ and after 30 days of storage, $100 \%$ mortality of populations of insects were observed in all cocoa beans stored in SGB liners except one single bag in which a few individual insects were alive (Jonfia-Essien et al., 2008b).

Other major applications of hermetic storage. Starting in 2003, the International Rice Research Institute (IRRI) proved that hermetic storage of paddy and rice seed using 5 tonne Cocoons

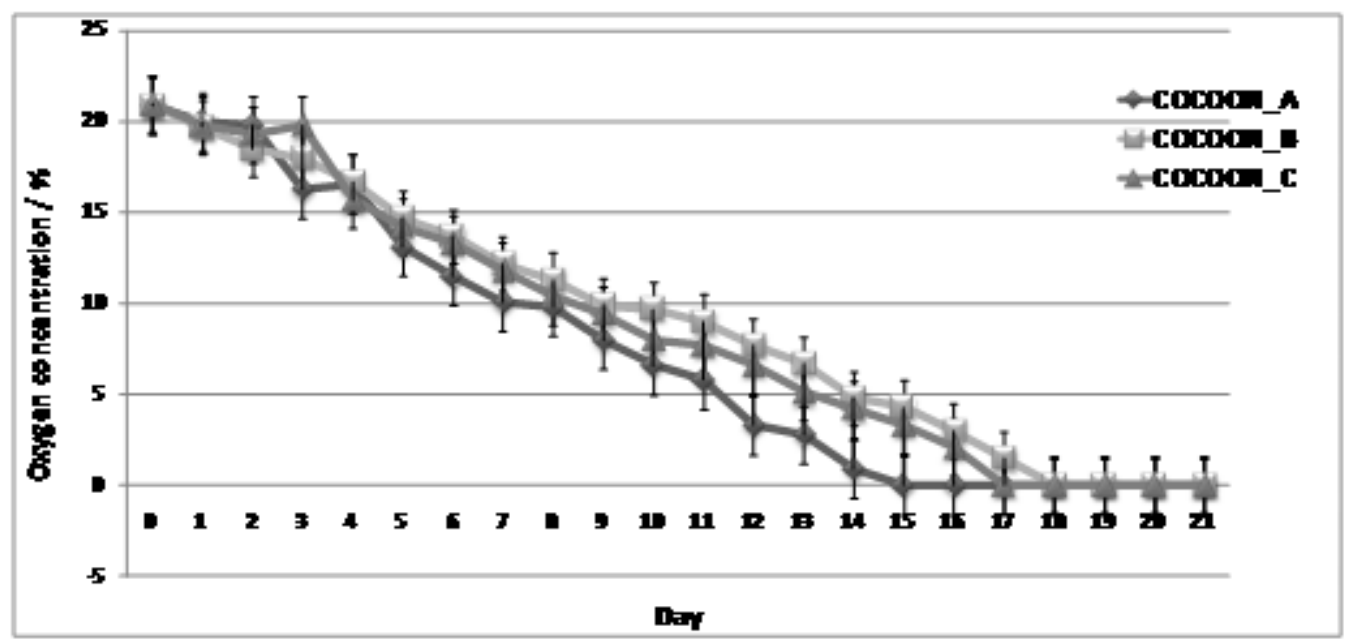

Figure 7. Daily oxygen concentrations inside the $\mathrm{Cocoon}^{\mathrm{TM}}$ over the hermetic storage period of cocoa beans stored in Ghana (Jonfia - Essien et al., 2008a). 
TABLE 1. Mean mortality after nine weeks of storage of cocoa beans stored in Ghana (Jonfia - Essien et al., 2008a)

\begin{tabular}{lcccc}
\hline Cocoon & Period (weeks) & Sub-plot & Lasioderma serricorne & Tribolium castaneum \\
\hline A & 3 & 1 & $90 \pm 0.2$ & $82 \pm 0.2$ \\
& 2 & $90 \pm 0.1$ & $84 \pm 0.4$ \\
& 3 & $88 \pm 0.2$ & $82 \pm 0.2$ \\
B & 1 & $100 \pm 0.0$ & $100 \pm 0.0$ \\
& 6 & 2 & $100 \pm 0.0$ & $100 \pm 0.0$ \\
& & 3 & $100 \pm 0.0$ & $100 \pm 0.0$ \\
C & 1 & $100 \pm 0.0$ & $100 \pm 0.0$ \\
& 9 & 2 & $100 \pm 0.0$ & $100 \pm 0.0$ \\
& & 3 & $100 \pm 0.0$ & $100 \pm 0.0$ \\
\hline
\end{tabular}

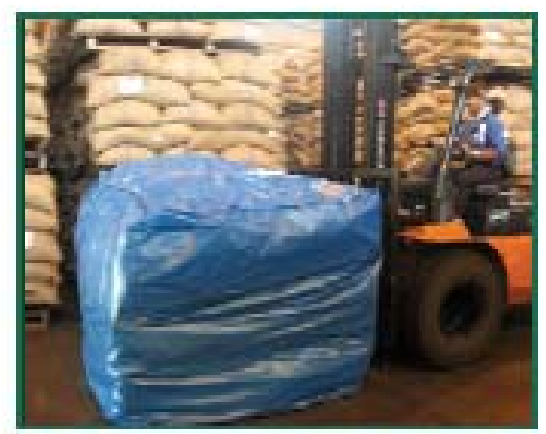

Figure 8. Cocoa in SuperGrainbag-HC, 1 tonne, Singapore, 2009.

produced results equivalent to storing under air conditioned conditions or refrigerated storage for periods of up to a year. Later, IRRI showed safe storage in the smaller SuperGrainbags $(60 \mathrm{~kg})$ (Rickman and Aquino, 2004; Villers and Gummert, 2009). Other studies on hermetic storage of rice and corn seed in Mexico, Thailand, Bangladesh, and Cambodia showed similar results for periods of 90-280 days with germination rates at the end of the period from 95 to $98.3 \%$. SuperGrainbags are now used on a large scale by Bayer CropSciences for rice seed storage in the Philippines, India, Indonesia and Brazil.

Coffee storage using Cocoons or SuperGrainbags up to a year while maintaining quality has been used since 2005 (Aronson et al., 2005). This process protects coffee against deterioration of quality as determined by cupping tests and is now used in some 12 countries.

Hermetic corn storage on a large scale (Fig. 1 ), has been used in such places as the Philippines, Rwanda and Thailand (Villers et al., 2008). In Ghana, several hundred thousand are sold at retail for small farmers for corn, sorghum and bean storage.

Beans and sorghum stored in large Cocoons $^{\mathrm{TM}}$ for up to one year have been used on a large scale in Rwanda and Ghana (Villers et al., 2008). Field trials in Costa Rica have shown that beans stored hermetically in Cocoons for 3 months not only are well preserved and insectfree but the otherwise doubling of required cooking time after 3 months of conventional storage is eliminated. More recently, in 2009, initial trials in Kerala, India have shown promising results in storing tea, maintaining essential constant moisture content as well as taste, color and texture for 4 months (private communication from Avinish). Indian subcontinent regional sales manager, GrainPro Inc.

\section{CONCLUSIONS}

Hermetic is a successful storage method for the protection of commodities, replacing fumigants for insect control and for quality preservation of 
stored products. Hermetic storage is achieved in specially constructed plastic structures. Plastic structures suitable for long-term storage systems, as well as intermediate storage of grain have been developed and applied. Flexibility, transportability, ease of erection, simplicity of operation and maintenance and durability are distinct advantages. Their availability in various sizes, capacities and forms can suit a wide range of requirements to fit several levels of operation.

The use of hermetic structures made of gastight flexible plastic liners can be a safe and viable alternative to permanent rigid structures for organic protection of cocoa beans for extended periods and it seems to be the most promising method for storing cocoa beans. Aside from controlling insect population it is more economical and convenient. The usage of hermetic storage for cocoa beans is highly practical and technically feasible.

\section{REFERENCES}

Aronson, S., Raudales, R., Trubey, R. and Villers, P. 2005. Breakthrough in storing high quality coffee. Tea \& Coffee Trade Journal 177(11). pp. 32 - 37.

Cao, Y., Song, Y. and Sun, G. 2003. A survey of psocid species infesting stored grain in China and resistance to phosphine in field populations of Liposcelis entomophila. In: Credland, P.F., Armitage, D.M., Bell, C.H., Cogan, P.M., Highley, E. (Eds.), pp. 662-667. Advances in Stored Product Protection, Proceedings of the 8th International Working Conference on Stored-product Protection, York, CAB International, Oxon, UK.

Ferizili, A. G. and Emekei, M. 2000. Carbon dioxide fumigation as a methyl bromide alternative for the dried fig industry, G. L. Obenauf and R. Obenauf (Eds.), pp. 81. Annual International Research Conference on Methyl Bromide Alternatives and Emissions Reductions, Orlando, Florida.

GrainPro, 2008. TranSafeliners, GrainPro publication, http://www.grainpro.com/ products.html\#TSL

Jonfia-Essien, W. A., Navarro, S. and Dator, J.V. 2008a. Effectiveness of hermetic storage in insect control and quality preservation of cocoa beans in Ghana. In: Daolin., G., Navarro, S., Jian, Y., Cheng, T., Zuxun, J., Yue, L., Haipeng, W. (Eds.), pp. 305-310. Proceedings of the $8^{\text {th }}$ International Conference on Controlled Atmosphere and Fumigation in Stored Products. California Garden Hotel, Chengdu, China. Sept. 21-26. 2008, Sichuan Publishing Group, Sichuan, China.

Jonfia-Essien, W. A., Navarro, S. and Dator, J.V. 2008b. SuperGrainBag: a hermetic bag liner for insect control of stored cocoa beans in Ghana. In: Daolin., G., Navarro, S., Jian, Y., Cheng, T., Zuxun, J., Yue, L., Haipeng, W. (Eds.), pp. 290-293. Proceedings of the $8^{\text {th }}$ International Conference on Controlled Atmosphere and Fumigation in Stored Products. California Garden Hotel, Chengdu, China. Sept. 21-26. 2008, Sichuan Publishing Group, Sichuan, China.

Navarro, S. 2006. Modified Atmospheres for the Control of Stored-Product Insects and Mites. In: Insect Management for Food Storage and Processing, Second Edition. Heaps, J. W. Ed., AACC International, St. Paul, MN. pp. 105146.

Navarro, S., Varnava, A. and Donahaye, E. 1993. Preservation of grain in hermetically sealed plastic liners with particular reference to storage of barley in Cyprus. In: Navarro, S. and Donahaye, E. (Eds.), pp. 223-234. Proceedings of the International Conference on Controlled Atmosphere and Fumigation in Grain Storages, Winnipeg, Canada, June 1992 , Caspit Press Ltd., Jerusalem.

Navarro, S., DeBruin, T., Montemayor, A. R., Finkelman, S., Rindner, M. and Dias, R. 2007. Use of biogenerated atmospheres of stored commodities for quality preservation and insect control, with particular reference to cocoa beans. In: S. Navarro, C. Adler, J. Riudavets, V. Stejskal (Eds.), Proceedings of the Conference of the International Organization for Biological and Integrated Control of Noxious Animals and Plants (IOBC). West Palaearctic Regional Section (WPRS) (OILB SROP) Working Group on Integrated Protection of Stored Products Bulletin Vol. 30 (2), 2007, Prague, Czech Republic, September 20-23, 2005. 
Navarro, S., Donahaye, E., Caliboso, F.M. and Sabio, G.C. 1995. Application of modified atmospheres under plastic covers for prevention of losses in stored grain. Final Report submitted to U.S. Agency for International Development, CDR Project No. C7-053, August 1990 - November 1995. 32 pp.

Navarro, S., Donahaye, E., Kashanchi, Y., Pisarev, V. and Bulbul, O. 1984. Airtight storage of wheat in a P.V.C. covered bunker. In: B. E. Ripp, H. J. Banks, D. J. Calverley, E. G. Jay, and S. Navarro (Eds.), pp. 601-614. Proceedings of the Internationa Symposium on Practical Aspects of Controlled Atmosphere and Fumigation in Grain Storages. Elsevier, Amsterdam.

Navarro, S., Finkelman, S., Sabio, G., Iskber, A., Dias, R., Rindner, M. and Azrieli, A. 2002. Enhanced effectiveness of vacuum or $\mathrm{CO} 2$ in combination with increased temperatures for control of storage insects. Presented in Advances in Stored Product Protection. In: Proceedings of the $8^{\text {th }}$ International Working Conference on Stored Product Protection (IWCSPP). pp. 818-822.

Rickman, J.F. and Aquino, E. 2004. Appropriate Technology for Maintaining Grain Quality in Small-scale Storage. Donahaye, E.J., Navarro, S., Bell, C., Jayas, D., Noyes, R., Phillips, T.W. [Eds.] (2007), pp. 149-157. Proceedings of the International Conference on Controlled Atmosphere and Fumigation in Stored Products, Gold-Coast Australia 8-13 ${ }^{\text {th }}$ August 2004.. FTIC Ltd. Publishing, Israel. http:// www.ftic.info/CAFsite/CAF.html

Sabio, G. C., Dator, J. V., Orge, R. F., Julian, D. D. T., Alvindia, D. G., Miranda, G. C. and Austria, M. C. 2006. Preservation of Mestizo 1 (PSB Rc72H) Seeds Using Hermetic and Low Temperature Storage Technologies. In: Lorini, I. et al. (Eds.), pp. 946-955. Proceedings of the $9^{\text {th }}$ International Working Conference on Stored Products Protections Campinas, Sao Paulo, Brazil, ABRAPOS.

Savvidou, N., Mills, K.A. and Pennington, A. 2003. Phosphine resistance in Lasioderma serricorne (F.) (Coleoptera: Anobiidae). In: Credland, P.F., Armitage, D.M., Bell, C.H.,
Cogan, P.M., Highley, E. (Eds.), pp. 702-712. Advances in Stored Product Protection, Proceedings of the 8th International Working Conference on Stored-product Protection, York, CAB International, Oxon, UK.

Transport Information Service, 2009. Cocoa/ Cocoa beans, Cargo loss prevention information from German marine insurers. http://www.tis-gdv.de/tis_e/ware/genuss/ kakao/kakao.htm

UNEP, 2002. United Nations Environment Programme. Montreal Protocol on Substances that Deplete the Ozone Layer, 2002 Assessment, Methyl Bromide Technical Options Committee. Nairobi, Kenya.

Varnava, A. and Mouskos, C. 1997. 7-Year Results of Hermetic Storage of Barley Under PVC Liners: Losses and Justification for Further Implementation of This Method of Grain Storage. In: Donahaye, E. J., Navarro, S. and Varnava, A. (Eds.), pp. 183-190. Proceedings of the International Conference on Controlled Atmosphere and Fumigation in Stored Products, 21-26 April 1996, Printco Ltd., Nicosia, Cyprus.

Villers, P., De Bruin, T. and Navarro, S. 2006. Development and Applications of the Hermetic Storage Technology. In: Lorini, I. et al. (Eds.), pp. 719-729. Proceedings of the $9^{\text {th }}$ International Working Conference on Stored Products Protections Campinas, Sao Paulo, Brazil, ABRAPOS.

Villers, P., Navarro, S.and DeBruin, T. 2008. Development of Hermetic Storage Technology in Sealed Flexible $\mathrm{S}$ t o $\mathrm{r}$ a g e Structures. In: Daolin., G., Navarro, S., Jian, Y., Cheng, T., Zuxun, J., Yue, L., Haipeng, W. (Eds.), pp. 36-37. Proceedings of the $8^{\text {th }}$ International Conference on Controlled Atmosphere and Fumigation in Stored Products. California Garden Hotel, Chengdu, China. September 21-26. 2008, Sichuan Publishing Group, Sichuan, China.Villers, P., Gummert, M., 2009, “Seal of Approval”, Rice Today, Jan-March 2009.

Villers, P. and Gummert, M. 2009. Seal of Approval. Rice Today, January - March 2009. pp. 36-37. 